\title{
Ab initio Calculation for Photochemistry of Psoralen Derivatives
}

\author{
Ja Hong Kim* and O Hyung Kwon \\ Department of Chemistry Education, Jeonbuk National University, Jeonju 561-756, Korea. *E-mail: kimjh@jbnu.ac.kr \\ Received April 26, 2011, Accepted June 9, 2011
}

Key Words : Ab initio, $\mathrm{C}_{4}$-cycloaddition, Thy $<>5$-MOP $<>$ Thy

Psoralens $(\mathrm{Ps})^{*}$ are a class of heterocyclic aromatic compounds that have been extensively utilized in the photochemotherapy of skin disorders such as psoriasis and vitiligo, ${ }^{1,2}$ cutaneous T-cell lymphoma. ${ }^{3}$ On exposure to ultraviolet light, especially in the range of 320-400 nm, psoralens form chemical crosslinks to the DNA bases in the three steps. ${ }^{4-8}$ The first step is intercalation of psoralen between to adjacent base-pairs. The second step is formation of monoadduct; that is one psoralen molecule photo-react with one strand of DNA. The third step is the cross-linking of the same psoralen molecule to the other strand of DNA, thus covalently linking the two strand of a double stranded DNA.

Psoralens have two photochemical reaction sites, 3,4pyrone double bond and 12,13-furan double bond, both of which are engaged in cross-linking of DNA bases. The formation of interstrand cross-linking through $\mathrm{C}_{4}$-cycloaddition of 3,4- and 12,13-double bonds to the 5,6-double bond of the pyrimidine bases, especially thymine, in DNA has been correlated with the biological effects of photoexcited psoralens.

Binding of Ps to $\mathrm{DNA}^{9}$ is generally the consequence of two successive events ${ }^{10}(1)$ intercalation into DNA between the base pairs; and (2) photocycloaddition reaction of 3,4Pyrone double bond and/or 12,13-furan double bond with 5,6-double bond of thymine.

Although several photoproducts of purine bases from direct and photosensitized irradiation of purines are known, ${ }^{11}$ the photoaddition reaction between the excited psoralens and purine bases are not well understood.

In the present paper, we report that the formation of interstrand cross-linking through $\mathrm{C}_{4}$-cycloaddition of 3,4and 12,13-double bonds to the 5,6-double bond of the pyrimidine bases, especially thymine, in DNA is calculated by the ab initio method.

The molecular geometries are optimized at HF levels of theory with the $6-31 \mathrm{G}^{*}$ basis set by using the Gaussian 03 program. $^{12}$

The $6-31 \mathrm{G}^{*}$ optimizations of the final structures are done to include the effect of electron correlation and the basis set with polarization function.

The photosensitization activity of psoralens is generally correlated to their photoreactivity with pyrimidine bases in

Abbreviation: Ps. Psoralen, 5-MOP. 5-methoxypsoralen, Thy. Thymine, $\diamond$. photocycloaddition
DNA.

The cross-linkage is caused by the formation of cyclobutane adducts, which are produced by photoreactions of the psoralen 3,4-pyrone and 12,13-furan double bonds to two pyrimidine bases.

The association energies for photocycloadduct $(\Delta \mathrm{E})$ are obtained by subtracting the sum of the energies of the 5 MOP and two thymine from the energy of the full optimized photocycloadduct.

$$
\begin{aligned}
\Delta \mathrm{E}= & \{\mathrm{E}(\text { Thy }<>(3,4) 5-\mathrm{MOP}(12,13)<\mathrm{Thy})\}-\{\mathrm{E}(5- \\
& \mathrm{MOP})+\mathrm{E}(\text { Thy }) \times 2\}
\end{aligned}
$$

Gibbs free energies $\left(\Delta \mathrm{G}^{\circ}\right)$ for structures involved in 5MOP, thymine and photocycloaddition paths are calculated by following equation.

$$
\begin{aligned}
\Delta \mathrm{G}^{\circ}= & \left\{\Delta \mathrm{G}_{\mathrm{f}}^{\circ}(\text { Thy }<(3,4) 5-\mathrm{MOP}(12,13) \diamond \mathrm{Thy})\right\} \\
& -\left\{\Delta \mathrm{G}_{\mathrm{f}}^{\circ}(5-\mathrm{MOP})+\Delta \mathrm{G}_{\mathrm{f}}^{\circ}(\text { Thy }) \times 2\right\}
\end{aligned}
$$

The association energies for photocycloadducts of Thy $\diamond(3,4) 5-\operatorname{MOP}(12,13) \diamond$ Thy are summarized in Table 1 .

\begin{tabular}{|c|c|c|c|c|}
\hline Photocycloadducts & $\begin{array}{c}\mathrm{E} \\
\text { (Hartree) }\end{array}$ & $\begin{array}{c}\Delta \mathrm{G}_{\mathrm{f}}^{\mathrm{o}} \\
\text { (Hartree) }\end{array}$ & $\begin{array}{c}\Delta \mathrm{E} \\
(\mathrm{kcal} / \mathrm{mol})\end{array}$ & $\begin{array}{c}\Delta \mathrm{G}^{\circ} \\
(\mathrm{kcal} / \mathrm{mol})\end{array}$ \\
\hline (cis anti)(cis anti) & -1660.736581 & -1660.343760 & 28.053 & 61.247 \\
\hline (cis anti)(cis syn) & -1660.744099 & -1660.349372 & 23.336 & 57.726 \\
\hline (cis anti)(trans anti) & -1660.748974 & -1660.353979 & 20.277 & 54.835 \\
\hline (cis anti)(trans syn) & -1660.750743 & -1660.355176 & 19.167 & 54.084 \\
\hline$($ cis syn)(cis anti) & -1660.745445 & -1660.351619 & 22.491 & 56.316 \\
\hline$($ cis syn)(cis syn) & -1660.739044 & -1660.346261 & 26.508 & 59.678 \\
\hline (cis syn)(trans anti) & -1660.742952 & -1660.351247 & 24.056 & 56.549 \\
\hline$($ cis syn)(trans syn) & -1660.747089 & -1660.352682 & 21.460 & 55.649 \\
\hline (trans anti)(cis anti) & -1660.750950 & -1660.355593 & 19.037 & 53.822 \\
\hline (trans anti)(cis syn) & -1660.745803 & -1660.351867 & 22.267 & 56.160 \\
\hline (trans anti)(trans anti) & -1660.743010 & -1660.350093 & 24.019 & 57.273 \\
\hline (trans anti)(trans syn) & -1660.746736 & -1660.354303 & 21.681 & 54.632 \\
\hline$($ trans syn)(cis anti) & -1660.748735 & -1660.354303 & 20.427 & 54.632 \\
\hline (trans syn)(cis syn) & -1660.746427 & -1660.351802 & 21.875 & 56.201 \\
\hline (trans syn)(trans anti) & -1660.745146 & -1660.352907 & 22.679 & 55.508 \\
\hline (trans syn)(trans syn) & -1660.751893 & -1660.357472 & 18.445 & 52.643 \\
\hline
\end{tabular}

Table 1. Energy and Gibbs free energy of Thy $\diamond(3,4) 5-\mathrm{MOP}$ $(12,13)<>$ Thy at $\mathrm{HF} / 6-31 \mathrm{G}^{*}$ level

$\left(1\right.$ Hartree $\left.=4.3597482 \times 10^{-18} \mathrm{~J} / \mathrm{mol}=627.5095 \mathrm{kcal} / \mathrm{mol}\right)$ 


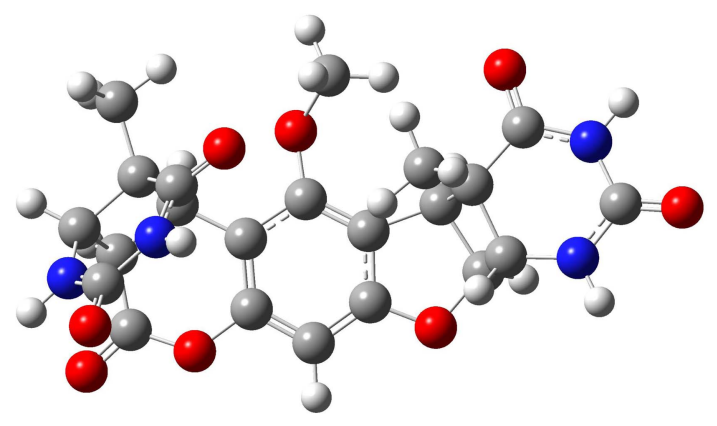

(cis anti)Thy<>(3,4)5-MOP $(12,13)<>$ Thy (trans syn)

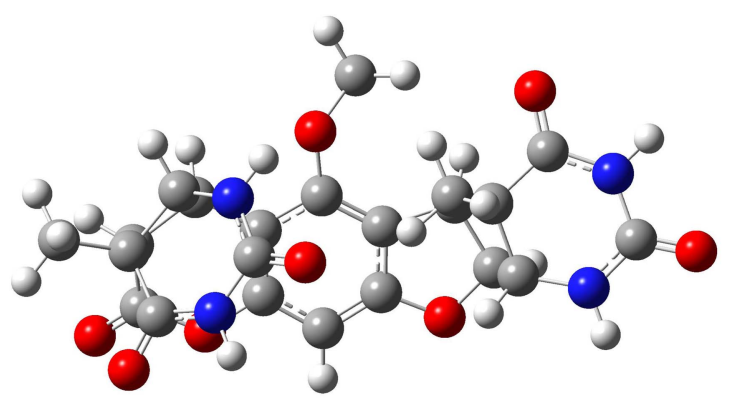

(cis syn)Thy<>(3,4)5-MOP $(12,13)<>$ Thy (trans syn)

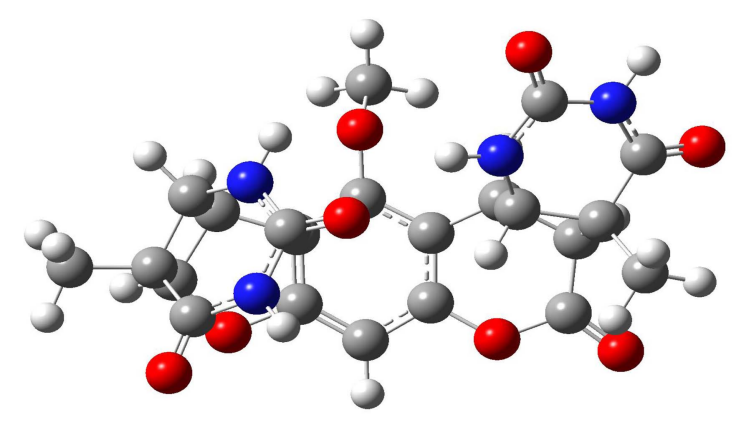

(trans anti)Thy<>(3,4)5-MOP $(12,13)<>$ Thy (cis anti)

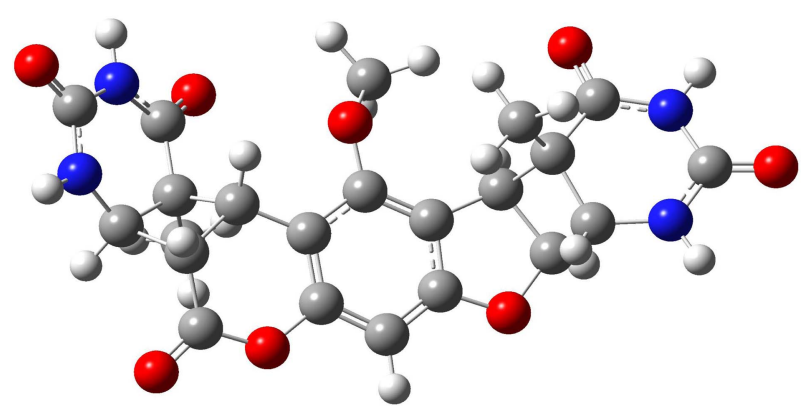

(trans syn)Thy<>(3,4)5-MOP $(12,13)<>$ Thy(trans syn)

Figure 1. The four possible photocycloadducts photocycloadducts of Thy $\diamond(3,4) 5-\operatorname{MOP}(12,13)<>$ Thy by HF/6-31G* . of Thy $<>(3,4) 5-\operatorname{MOP}(12,13) \diamond$ Thy are shown in Figure 1 .

As shown in Table 1, there are four types of photoisomer, (cis anti)Thy $\diamond(3,4) 5-\operatorname{MOP}(12,13) \diamond$ Thy, (cis syn)Thy $\diamond$ $(3,4) 5-\mathrm{MOP}(12,13) \diamond$ Thy, (trans anti)Thy $\diamond(3,4) 5-\mathrm{MOP}$ $(12,13) \diamond$ Thy, (trans syn)Thy $\diamond(3,4) 5-\mathrm{MOP}(12,13)$ Thy cycloadducts.

The association energy (E) of these photocycloadducts in (cis anti)Thy $<>(3,4) 5-\mathrm{MOP}(12,13)<>$ (trans syn) Thy structure is $19.167 \mathrm{kcal} / \mathrm{mol}$. The Gibbs free energies $\left(\Delta \mathrm{G}^{\circ}\right)$ is $54.084 \mathrm{kcal} / \mathrm{mol}$. This result indicate that the most probable photocycloadduct is (trans syn)Thy $>(3,4) 5-\mathrm{MOP}(12,13)$ $<>$ Thy.

The $\Delta \mathrm{E}$ and $\Delta \mathrm{G}^{\circ}$ for (cis syn)(trans syn) structures are $21.460 \mathrm{kcal} / \mathrm{mol}, 55.649 \mathrm{kcal} / \mathrm{mol}$ respectively. This tendency is similar to that obtained for the photocycloadducts for (trans anti)(trans syn) are $21.681 \mathrm{kcal} / \mathrm{mol}(\Delta \mathrm{E}), 54.632$ $\mathrm{kcal} / \mathrm{mol}\left(\Delta \mathrm{G}^{\circ}\right)$ and (trans syn)(trans syn) are $18.445 \mathrm{kcal} /$ $\operatorname{mol}(\Delta \mathrm{E}), 52.643 \mathrm{kcal} / \mathrm{mol}\left(\Delta \mathrm{G}^{\circ}\right)$ respectively.

The optimized geometrical structures for possible photocycloadducts are shown in Figure 1. The most stable photocycloadduct is (trans syn), (trans syn), in Thy $<(3,4) 5$ $\operatorname{MOP}(12,13)<$ Thy by HF/6-31G .

Comparison of these energy values with available experiment shows that the photocycloaddition can explain the photocrosslink Thy $<>$ Ps $<>$ Thy completely. Therefore, this study will give a better understanding of the photocycloaddtion reaction of psoralens derivatives with detailed molecular model. ${ }^{13}$

Acknowledgments. This paper was supported by research funds of Jeonbuk National University in 2009.

\section{References}

1. Parrish, J. A.; Fitzpatrick, T. B.; Tanenbaum, L.; Pathak, M. A. N. Engl. J. Med. 1974, 291, 1207.

2. El Mofty, A. M. Egypt Med. Assoc. 1948, 31, 651.

3. Dall'Acqua, F.; Terbojevich, M.; Benveneto, F. Z. Naturforsch. Teil B 1968, 23, 943.

4. Dall'Acqua, F.; Marciani, S.; Rodighiero, G. FEBS Letters 1970, 9 , 121.

5. Dall'Acqua, F.; Marciani, S.; Ciavatta, L.; Rodighiero, G. Z. Naturforsch. Teil B 1971, 26, 561.

6. Isaacs, S. T.; Shen, C. K.; Hearst, J. E.; Rapoport, H. Biochemistry 1977, 16, 1058.

7. Johnston, B. H.; Jhonson, M. A.; Moore, C. B.; Hearst, J. E. Science 1977, 197, 906.

8. Johnston B. H.; Kung, A. H.; Moore C. B.; Hearst, J. E. Biochemistry 1982, 21, 861.

9. Rodighiero, G.; Dall'Acqua, F.; Averbeck, D. Photobiology 1988, 1,37 .

10. Musajo, L.; Rodighiero, G. Photophysiology 1977, 7, 115.

11. Shim, S. C.; Jeon, Y. H.; Kim, D. W.; Hahn, G. S.; Yoo, D. J. J. Photosci. 1995, 2, 37.

12. Gaussian 03W and Gauss View 3.0, Gaussian: Inc. 2006.

13. Kim, J. H.; Kwon, O. H. J. Kor. Chem. Soc. 2009, 53, 244. 